\title{
Using Multiple Intelligences Approach in Designing Classroom Activities
}

\author{
Andreas Winardi \\ Duta Wacana Christian University, Yogyakarta, Indonesia
}

\begin{abstract}
In 1983, Horward Gardner, a professor of education at Harvard Universiy introduced the theory of Multiple Intelligence. This theory states that people have a unique blend of capabilities and skills (intelligences). In the classroom context, it implies that students possess different kinds of minds and therefore learn, remember, perform, and understand in different ways. Based on the theory, Gardner challenged the previous practices that gauged intelligence using IQ test which focused more on the ability to use language and/or logic. According to him, the measurement of people's intelligence should not be limited to linguistic and logical-mathematical abilities only, but should also cover other abilities. In addition to language and logic, Gardner proposed six other intelligences, which in the past were known as aptitudes or interests, namely: Visual-Spatial Intelligence, Musical Intelligence, Bodily-Kinesthetic Intelligence, Intrapersonal Intelligence, Interpersonal Intelligence, and Naturalist Intelligence. As an English teacher, we often have to deal with the fact that our classes consist of students who posses different intelligences. To help the students reach their maximum learning potential, teacher needs to respect students' uniqueness and accommodate the variety of intelligences. This can be done by applying multiple intelligences approach in designing classroom activities.
\end{abstract}

Keywords: multiple intelligences, approach, classroom activities

\section{Introduction}

One of the most common problems encountered by English teachers is teaching mixed-ability classes. This phenomenon becomes more problematic because the students may also have different learning styles and motivation. Some of the teachers who do not know to handle these differences tend to take an easy way by treating the heterogeneous classes as homogeneous ones. These teachers, according to Lane $(2000$, p. 2, in Fitria, 2013) "will ask their students to sit in seats and listen to all the material delivered by the teacher all the time". As a result, most students fail to manifest their true potential.

Regarding this issue, Fitria (2013) suggested that students must be given opportunities for the creative exploration of their individual interest and talents. These opportunities are important to stimulate students to do their best performance. One of the ways to do so is by using Multiple Intelligences approach in the classroom.

Multiple Intelligences approach recognizes and respects various interests and intelligences. It realizes that students have different ways of absorbing/learning the lesson. Therefore, teachers who support Gardner's theory will use many different activities to cater for students' individual needs, strengths, and weaknesses. In line with this, Widiatmoko (2013) asserted that "by experiencing various tasks exposing different application of

Andreas Winardi, lecturer, M.A., English Department, Duta Wacana Christian University. 
MI in the lesson, students are more likely to experience more opportunities to maximize their learning potentials" (p. 216).

\section{Description of the Eight Intelligences}

Thomas Armstrong (1994, in Gonzales, 1999) described Gardner's seven intelligences. They are as follows:

(1) Linguistic Intelligence: The people who possess this intelligence are able to use words effectively, whether orally or in writing. Some professions which need strong linguistic intelligence, among others are: storyteller, orator, politician, poet, playwright, editor, or journalist.

(2) Logical-Mathematical Intelligence: This intelligence deals with the ability to use numbers effectively, and think logically. Mathematician, tax accountant, statistician, computer programmer, or logician belong to this category.

(3) Spatial-Intelligence. A hunter, scout, or guide need to have a good spatial intelligence. It means that they must be able to perceive the visual-spatial world accurately. People with the afore-mentioned professions tend to be more sensitive to color, line, shape, form, and space, and understand how these elements relate to each other. Similarly, an interior decorator, architect, artist, or inventor should possess this quality.

(4) Bodily-Kinesthetic Intelligence. We are often amazed to see how an actor, a mime, an athlete or a dancer move their body graciously. They are very adept at using their whole body to express their feelings and ideas. Likewise, a craftsperson, sculptor, mechanic, or surgeon has special skills in using their hands to produce or transform things. People with this ability is said to have a strong bodily-kinesthetic intelligence.

(5) Musical Intelligence. People who can play a musical instrument, sing a song, compose a song, perceive the sound, and discriminate the music are the ones who are blessed with musical intelligence.

(6) Interpersonal Intelligence: People who are good at interacting with others, understanding other people's feelings, moods, intentions, and motivations are interpersonally smart. They are able to read people's facial expressions, voice, and gestures and make appropriate responses to those cues.

(7) Intrapersonal Intelligence: People who are intra-personally intelligent are capable of understanding oneself, reflecting on his/her strengths and weaknesses, analyzing his/her own inner moods, intentions, motivations, temperaments, and desire.

In addition to what Amstrong described, Fitriani (2013) mentioned that people may also have Naturalist Intelligence. According to her, "people who have this intelligence will be able to observe patterns in nature, identifying and classiying objects, and understanding natural and human-made systems" (p. 249).

Regarding the application of Multiple Intelligences approach in the classroom, Covey (1998) posited that each student learns differently and he/she may maximize his/her learning potential through his/her most dominant intelligence. Furthermore, he suggested some activities for each intelligence that may help students get maximum benefits of their learning (Covey, 1998, p. 186).

(1) Linguistic: learn through reading, writing, and telling stories.

(2) Logical-Mathematical: learn through logic, patterns, categories, and relationships.

(3) Bodily-Kinesthetic: learn through bodily sensations and touching.

(4) Spatial: learn through images and pictures.

(5) Musical: learn through sound and rhythm.

(6) Interpersonal: learn through interaction and communication with others.

(7) Intrapersonal: learn through their own feelings. 


\section{Sample of Classroom Activities That Accommodate the Eight Intelligences}

Being the proponent of Gardner's theory, this semester (even semester 2014-2015), I tried to use MI approach in my English for International Communication Class (three credits) which consisted of 25 students. This class is designed to equip the students with necessary skills and strategies to communicate in international context. It gives a unique overview of English today as well as providing something of interest to everyone. In this paper, I take one of the lesson plans as a sample of how to design classroom activities to accommodate students' eight intelligences.

Table 1

English for International Communication Lesson Plan

\begin{tabular}{|l|l|}
\hline Topic & Crossing cultures \\
\hline Objective & To increase students' intercultural awareness \\
\hline Time & 150 minutes \\
\hline Number of students & 25 \\
\hline
\end{tabular}

\section{Naturalist Intelligence}

Teacher asks the students to go out and collect stones, flowers, leaves, etc. After the students come back to the class, they compare their collections with other students, and discuss how the objects differ in terms of shape, size, color, etc.

The students then discuss how differences can make our world more beautiful. The teacher tells them to imagine how boring it is if there is only one shape, one size, and one color in our lovely earth. The teacher can use the discussion to increase students' awareness that we may be culturally, socially and economically different from one another, but still we can live in harmony .

\section{Musical Intelligence}

Teacher plays a song: Black or White by Michael Jackson. This song is an excellent source to highlight the idea of equality among human race. It tells us that people can become brothers/sisters regardless of their origin, race, religion, skin color, etc.

Several activities can be done using this song as a material, such as: fill in the blank, arrange the jumbled lyrics, underline the adjectives, etc.

\section{Visual Spatial}

As mentioned before, we can strengthen students' visual-spatial intelligence by using images or pictures. In this lesson, teacher shows some pictures, and invites students to share what they see. For example:
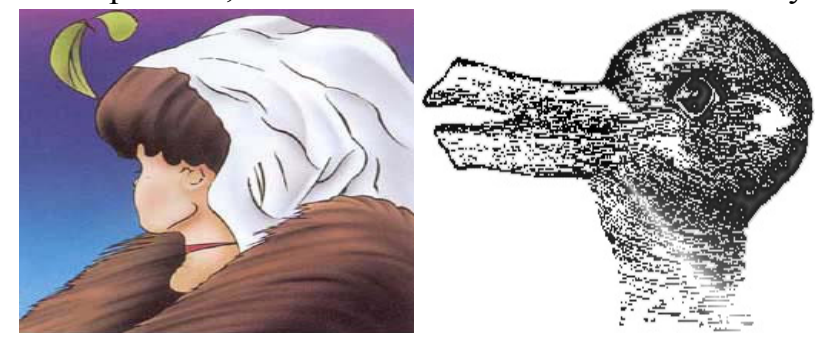

Figure 1. Optical illusions used to check students' point of view. ${ }^{1}$

\footnotetext{
${ }^{1}$ Dean, J. (2006). Young lady or an old hag? See www.moillusions.com/young-lady-or-old-hag. Weisstein, E. W. (2004). Rabbit-duck illusion. See mathworld.wolfram.com/Rabbit-DuckIllusion.html.
} 
Note: I have tried to use these pictures several times and I found out that although people looked at the same pictures, they tended to have different opinions regarding what they saw. Some were convinced that they stared at the pictures of a young girl and a rabbit. While others believed that those were the pictures of an old woman and a duck respectively. In fact, all opinions are correct - it is just a matter of point of view, from which angle the students look at the pictures.

This experience teach us not to easily judge others who have different opinions from us. We should try as much as we can to be an open-minded person, to be willing to respect others' point of view. Similarly, we need to appreciate other cultures.

\section{Logical Mathematical}

The teacher assigns the students to discuss the poem taken from The 7th Habits of Highly Effective Teens. The poem shows us that people often behave in illogical way.

\section{The Cold Within}

Six humans trapped by happenstance, in bleak and bitter cold, Each one possessed a stick of wood, or so the story told.

Their dying fire in need of logs, the first man held his back, For of the faces 'round the fire, he noticed one was black.

The next man looking 'cross the way saw one not of his church, And couldn't bring himself to give the fire his stick of birch.

The third one sat in tattered clothes, he gave his coat a hitch, Why should his log be put to use to warm the idle rich?

The rich man just sat back and thought of the wealth he had in store, And how to keep what he had earned from the lazy, shiftless poor.

The black man's bespoke revenge as the fire passed from sight, For aall he saw in his stick of wood was a chance to spite the white.

The last man of this forlorn group did naught except for gain, Giving only to those who gave was how he played the game.

Their logs held tight in death's still hand was proof of human sin,

They didn't die from the cold without—-they died from the cold within. (Covey, 1998, p. 192)

Use your logic to answer the following questions.

(1) Why did all people in the story die at the end?

(2) If you were there, what would you do to help remedy the situation?

(3) In this poem, people do not behave logically. Do you agree? Explain your answer.

\section{Bodily-Kinesthetic}

The students are divided into five groups consisting of five students. They are given an article about International Gesture Dictionary written by Roger Axtell (in Blanchard \& Root, 1996, pp. 11-13). The teacher assigns the students to read and discuss some of the gestures, for instance: group 1-discuss gestures No. 1-5; group 2-discuss gestures No. 6-10 and so on. After that, each group comes on "stage". One student reads the gestures and others perform the movements. For example: 
Table 2

Samples of Gestures, Countries, and Their Meanings

\begin{tabular}{llll}
\hline No. & Name of the gesture & Country & Meaning \\
\hline 1. & Eyebrow raise & Tonga & "Yes" or "I agree" \\
& Peru & "Money" or "Pay me" \\
10. & Cheek stroke & Greece, Italy, Spain & "Attractive" \\
\hline
\end{tabular}

To make the lesson more interesting, the activity can be followed by a game. The teacher asks each group to send one representative to come to the front of the class. After all are ready, the teacher mentions the name of a gesture, for example: cheek stroke! The people in front of the class compete to perform the gesture correctly. The fastest person to do it accurately can go back to his/her seat.

\section{Interpersonal Intelligence}

Strengthening interpersonal intelligence requires interaction among members of the class. One of the interactive activities that we can use is "I spy game". The activity goes as follow: Teacher divides students into several "tribes" or "kingdoms". Each new "tribe" or "kingdom" then creates their own set of "customs". For example:

(1) People in our kingdom never shake hands with a stranger. As a greeting, we touch the stranger's cheek.

(2) It is considered impolite in our culture to look someone at the eye.

(3) It is normal for us to shout to each other.

$\cdots$

After each "tribe" or "kingdom" finishes creating its set of customs, the kingdom assigns one of its member to become a spy, to observe other cultures. The spy then goes from one kingdom to another kingdom: observing, learning, and interacting with people from other culture. Finally, the spy shares his/her experience to the whole class.

\section{Intrapersonal Intelligence}

Teacher asks students to make a reflection:

(1) Do I feel reluctant to interact with people from other culture?

(2) How do I treat people from other culture?

(3) After learning about their culture, how do I feel?

$\cdots$

\section{Linguistic Intelligence}

To conclude the lesson, students are given an opportunity to deliver a speech about the importance of appreciating other culture. To make the activity more interesting and alive, students are divided into groups of three, and they have to give speech in three different languages.

\section{Conclusion}

It is our duty as a teacher to ensure that our students make a significant improvement in their learning. This is not an easy task since each student may have his/her own preference, style, speed, and motivation in digesting the materials. Hence, teachers need to devise a strategy to cope with the differences. According to Hafifah (2013), "Multiple Intelligence Strategy give teachers the chance to discover, value and enhance the talents of all learners through eight different intelligences they have" (p. 79). 
Designing classroom activities using Multi Intelligences approach is an effort to strengthen students' dominant intelligence and develop their weak intelligence. By doing so, it is expected that students' potential in learning English can be maximized to the fullest.

\section{References}

Blanchard, K., \& Root, C. (1996). For your information 2. New York: Addison-Wesley Publishing Company, Inc..

Covey, S. (1998). The 7 habits of highly effective teens. New York: Simon \& Schuster, Inc..

Fitria, G. A. (2013). Bringing multiple intelligence principles as a basis of creating media in ELT classroom. In B. Y. Cahyono and F. Megawati (Eds), Materials and media in English language teaching. Malang: State University of Malang Press.

Gonzalez, J. B., \& Blau, E. K. (1999). Building on basics: A thematic approach to reading comprehension. New York: Addison Wesley Longman, Inc..

Hafifah, G. N. (2013). Multiple Intelligences approach in communicative language teaching. Proceeding of the International Conference on English Linguistics and Literature: The Multifaced Dimensions of Linguistics and Literature, English Language and Letters Department Faculty of Humanities, Maulana Malik Ibrahim State Islamic University of Malang, Malang.

Widiatmoko, P. (2013). Accommodating students' multiple intelligences in planning a lesson. Proceeding of the International English Applied Linguistics Seminar and Workshop (TIEALLSAW) "Positioning the students at the centre Stage: How can educators help students learn English optimally?”, English Education Program, Galuh University, Ciamis. 